\title{
LA REPRESENTACIÓN POLÍTICA EN ESPAÑA DURANTE LA DICTADURA DE PRIMO DE RIVERA
}

\author{
A representação política na Espanha durante a ditadura de Primo \\ de Rivera \\ Political representation in Spain during the dictatorship of Primo \\ de Rivera
}

Miguel ÁNGEL GimÉNEZ MARTíNEZ ${ }^{I^{*}}$

http://dx.doi.org/10.1590/\$2178-14942018000200002

\footnotetext{
' Universidade Autônoma de Madri - Espanha.

*PhD em história pela Universidade de Castilla-la Mancha e pesquisador do programa "Juan de la Cierva" na Universidade Autônoma de Madri. (miguelangelgimenezmartinez@gmail.com)

Artigo recebido para publicação em 26 de junho de 2018 e aprovado para publicação em 29 de maio de 2018.
} 


\title{
RESUMEN
}

La dictadura de Miguel Primo de Rivera supuso el ensayo, por primera vez en España, de fórmulas representativas alejadas del modelo liberal parlamentario. La asunción de postulados corporativos, fundamentados en una concepción orgánica de la sociedad, permitió la creación de la Asamblea Nacional Consultiva, cuerpo llamado a colaborar en las tareas de gobierno y ofrecer una salida constitucional a la dictadura. Esta asamblea llegó a alumbrar un anteproyecto de Constitución en el que se preveían unas Cortes de tintes corporativos que, sin embargo, no llegaría a aprobarse. Combinando la exégesis de textos jurídicos, la revisión de los diarios de sesiones y el contraste con las aportaciones doctrinales, este artículo estudia la naturaleza, composición, organización y funciones de estos órganos, así como el papel político que desempeñaron dentro del esquema de poder de la época.

PalabRAS ClaVe: Corporativisma, Representadón política; Parlamenta, Dictadura; Primo de Rivera; España; Siglo XX.

\section{RESUMO}

A ditadura de Miguel Primo de Rivera representou, pela primeira vez na Espanha, a implementação de fórmulas representativas distantes do modelo liberal parlamentar. A escalada de ideias corporativas, fundamentadas numa concepção orgânica da sociedade, permitiu a criação da Assembleia Nacional Consultiva, criada para apoiar as propostas do governo e oferecer uma saída constitucional para a ditadura. Tal assembleia chegou a possibilitar um anteprojeto de Constituição no qual se previam cortes corporativas, as quais, no entanto, nunca chegaram a ser aprovadas. Combinando a exegese de textos jurídicos, a revisão do direito de sessões e o contraste com as contribuições doutrinárias, este artigo estuda a natureza, a composição, a organização e as funções desses órgãos, assim como o papel político que desempenharam dentro do esquema de poder da época.

\section{PALAVRAS-CHAVE: Corporativismo Representação política; Parlamenta Ditadura Primo de Rivera; Espanha; SéculoXX}

\begin{abstract}
The dictatorship of Miguel Primo de Rivera put into practice, for the first time in Spain, a representative system away from the liberal parliamentary model. The acceptance of corporative principles, based on an organic conception of society, allowed for creating the National Consultative Assembly, a non-legislative body destined to cooperate in government tasks and provide a constitutional way out from dictatorship. An assembly that came to conceive a draft constitution in which the Cortes was planned with a corporatist character. Combining the exegesis of legal texts, the review of records of sessions and the contrast with doctrinal contributions, this article studies the nature, composition, organization and functions of these bodies, as well as the political rule they carried out within the structure of power at that time.
\end{abstract}

\section{KeYwORDS: Corporatism Political representation; Parliament; Didatorship; Primo de Rivera; Spain; $20^{\text {th }}$ century.}




\section{LA QUIEBRA DEL RÉGIMEN REPRESENTATIVO LIBERAL}

E I golpe de Estado de 13 de septiembre de 1923 supuso la liquidación del régimen parlamentario en España y su sustitución por un directorio presidido por el general Miguel Primo de Rivera e integrado por nueve vocales en representación de las ocho regiones militares y la Armada (Tusell, 1987, p. 230 y ss.). Un decreto dictado cuatro días después disolvió las instituciones representativas previstas en la Constitución de 1876 — cortes, diputaciones, ayuntamientos - y otorgó a Primo de Rivera la facultad de proponer directamente al rey Alfonso XIII textos con valor de ley (García-Nieto, Donézar y López Puerta, 1973, p. 129). Eran los primeros pasos de un nuevo régimen en el que no tendría cabida la representación popular y que giraría en torno a la acción ejecutiva enérgica emprendida por el "cirujano de hierro", llamado a extirpar los problemas inmediatos que aquejaban al país.La dictadura de Primo de Rivera se enmarca, así pues, dentro de los parámetros ideológicos del regeneracionismo, que buscaba una reforma rápida y sustancial de las prácticas políticas —los considerados "excesos" del parlamentarismo- para acomodarlas al espíritu de la Constitución. No se buscaba, por lo tanto, la instauración de un régimen puramente fascista, pues aunque la Italia mussoliniana sirvió de inspiración simbólica y en ambos casos existió el miedo a una revolución proletaria, la dictadura española no contaba con una ideología previamente definida ni con un partido sólido que tomara el poder por la fuerza (Herr, 1977, p. 207; Ben-Ami, 1980; Tusell y Saz, 1982; Sueiro, 1983, p. 195-198; Peloille, 2005). La influencia del fascismo italiano en España de los años 1920 fue "marginal y sobrepuesta" (Gómez Navarro, 1991, p. 266) y no significó más que un "revulsivo ideológico y sociopolítico" sobre el preexistente bagaje contrarrevolucionario (Morodo, 1980, p. 10). En este sentido, resulta clara la distancia entre el Partito Nazionale Fascista y la Unión Patriótica, que no fue sino una organización creada desde el poder, carente de un programa coherente de gobierno, cuyos miembros abrigaban el deseo de alcanzar un puesto ventajoso en la estructura del Estado (Gómez Navarro, 1985; Martínez Segarra, 1992).

Primo de Rivera aprovechó en su favor el descrédito que durante la Restauración habían alcanzado las Cortes y el régimen representativo liberal. Así, cuando los presidentes de los últimos Congreso y Senado constitucionales —Melquíades Álvarez y el conde de Romanones, respectivamente - visitaron al rey poco después del levantamiento militar para exigirle la necesidad de reanudar las sesiones parlamentarias conforme a lo dispuesto en la Constitución de 1876, el dictador se permitió comentar: "El país no se impresiona ya con películas de esencias liberales y democráticas; quiere orden, trabajo y economía" (apud. Pemán, 1929, p. 30). Unas palabras que revelan el concepto autoritario de la política sostenido por el ge- 
neral, quien consideraba imposible arrancar la corrupción del régimen precedente si no era mediante un mando ejecutivo fuerte.

Sucede, sin embargo, que la autoridad ejercida sin control acaba por transformarse en tiranía, peligro contra el que tienen su razón de ser las Cámaras representativas en su lucha contra el poder personal. Para sustraerse a este riesgo, Primo de Rivera planteó su dictadura como una solución de carácter transitorio, que se prolongaría durante el tiempo preciso para "renovar" las instituciones del país. Pero ese planteamiento inicial fue traicionado por el propio dictador: la pasión por el poder le llevó a tratar de perpetuar su régimen buscando algún grado de participación del pueblo en el Estado. Es decir, intentó que - en terminología de Schmitt $\left(1968\right.$, cap. $\left.4^{\circ}\right)$ - la "dictadura comisoria" se convirtiera en "soberana", adentrándose en un círculo vicioso de difícil salida que afecta a casi todas las dictaduras: cuando tratan de introducir cauces representativos tienen que recurrir a vías de expresión propias de sistemas liberales, con lo que sus regímenes se convierten en híbridos y queda comprometida la eficacia ejecutiva que prometían.

Sin embargo, la representación es absolutamente necesaria para los gobernantes cuando ya no pueden apoyar su poder en las armas, motivo por el cual los dictadores necesitan para sí y para sus herederos algún grado de representación. De ahí que, pasado el tiempo en que Primo de Rivera tenía decidido dejar el poder, considerase la posibilidad de introducir una organización política estable a través de una Constitución plebiscitada, lo que a juicio de Sánchez Agesta (1974, p. 482) revela cómo sobre la dictadura "pesó el mito constitucional, como supuesto de muchos de sus actos y como crítica de su propia existencia".

Para preparar el terreno, Primo de Rivera sustituyó el 3 de diciembre de 1925 el directorio militar por otro civil que no perdió las máximas prerrogativas, incluyendo las legislativas. En esta misma línea se incardina el plebiscito celebrado entre el 10 y el 13 de septiembre de 1926, con el que se pretendía demostrar el índice de popularidad de la dictadura. Como explica Tuñón de Lara (1966, p. 157), "Ios Comités de Unión Patriótica y entidades oficiales dispusieron unas simples hojas en las que estampasen su firma los españoles de ambos sexos. Así fueron recogidas 6.697.164 firmas sin garantías ni comprobación en cuanto a la identidad de los firmantes ni a la forma de expresar su opinión".

Pero la iniciativa más importante para cumplir el propósito de "sustituir una dictadura militar por otra civil y económica" (apud. Díaz-Plaja, 1965, p. 68-70) fue la creación de un cuerpo unicameral "libre de la enrevesada filosofía y la humillante imitación del parlamentarismo liberal" (Gaceta de Madrid, 4-XII-1925, p. 1.219). Poco se sabía sobre la convocatoria, la elección y las facultades de la Cámara cuando Primo de Rivera lanzó la idea, pero la trayec- 
toria ideológica de las personas y colectivos que sostenían la dictadura hacía indicar que la organización de la representación política tendría los ingredientes propios del corporativismo (García Canales, 1977, p. 119-132; Fernández Sarasola, 2008, p. 900-906). Tradicionalistas, católicos y mauristas, que rechazaban por igual el parlamentarismo liberal, aprovecharon la indefinición de Primo de Rivera — cuya ideología era, a juicio de González Cuevas (2005, p. 101), una amalgama inclasificable de ideas hobbesianas, regeneracionistas y nacionalistas para poner en marcha su propio proyecto de representación política. En el campo carlista, hombres como Vázquez de Mella (1999, p. 119) o Pradera (1941, p. 220) consideraban el parlamentarismo incompatible con el "auténtico régimen representativo" que, a su juicio, se edificaba sobre bases orgánicas. Una representación que presuponía la participación en el Estado de "entidades naturales" tales como la familia o el municipio, desplazando cualquier fórmula asociativa artificial, como los partidos políticos. Desde el catolicismo social, Bofarull (1912, p. 117-137) reclamaba una representación orgánica de la sociedad más acorde con la tradición aristotélico-tomista. Y desde el maurismo, una de sus principales figuras, Goicoechea (1925, p. 69-70) proponía un "remedio higiénico" basado en la combinación de democracia individualista y democracia orgánica.

\section{LA ASAMBLEA NACIONAL CONSULTIVA}

T odos estos principios cristalizaron en el Decreto-Ley de 12 de septiembre de 1927 (Gaceta de Madrid, 14-IX-1927, p. 1.498-1.501), por el que se creaba la Asamblea Nacional Consultiva, a la que debían acudir los representantes de las diferentes clases e intereses de la nación. Una idea en la que insistiría el presidente de la Cámara, José Yangüas Messía, para quien la composición de la asamblea habría de responder a "una concepción orgánica en la que se advierte el propósito [...] de que concurran la representación del Estado, la del elemento individual y la del elemento corporativo público y social" (Diario de Sesiones de la Asamblea Nacional —en adelante DSAN_ , 10-X-1927, p. 8-9). La institución puesta en planta era, por lo tanto, de signo inequívocamente corporativo, una opción que a juicio de Mirkine-Guetzévitch (1928, p. 796) se había escogido para "someter a España a esa disciplina que la libre del virus democrático".

El Decreto-Ley estipulaba en su art. 15 que la asamblea habría de contar con un máximo de 375 y un mínimo de 325 integrantes, pero un decreto posterior (Gaceta de Madrid, 28IX-1927, p. 1.754) amplió el número de asambleístas a 400 al objeto de "dar representación y encaje a los elementos representativos de las entidades culturales". Por primera vez en la 
historia del parlamentarismo español (Giménez Martínez, 2017, p. 281) se permitió a las mujeres — previa autorización de sus maridos, siempre y cuando estos no formaran parte de la asamblea - integrar una cámara representativa: pertenecieron a ella un total de trece mujeres, la mayoría relacionada con el mundo de la educación, la cultura o la beneficencia, como Concepción Loring — primera mujer que hizo uso de la palabra en el hemiciclo—- María de Maeztu o Micaela Díaz Rabaneda (Díaz Fernández, 2005). El art. 15 del Decreto-Ley obligaba igualmente a los miembros de la asamblea a cumplir una serie de requisitos previos — ser español, contar más de 25 años y estar libre de sentencia condenatoria- y establecía como método de designación un orden acordado por el Consejo de Ministros, lo que anulaba de entrada cualquier posibilidad de que la Cámara pudiera servir de contrapeso al poder ejecutivo.

El art. 16 del Decreto-Ley especificaba cómo había de completarse la composición de la asamblea: un representante municipal y otro provincial por cada una de las provincias, un representante por cada organización provincial de la Unión Patriótica, una serie de representantes del Estado, una representación "por derecho propio" en virtud de las categorías y cargos ejercidos y una serie de representantes de condición diversa ligados a la cultura, la producción, el trabajo, el comercio y demás "actividades de la vida nacional" . A juicio de Morodo (1973, p. 86), Primo de Rivera introducía con todo ello una representación corporativa que consumaba una ruptura, si bien no radical todavía, con el modelo parlamentario y su presupuesto doctrinal y técnico: el sufragio individual, y ello porque la designación gubernativa — directa o indirecta- sustituía a la elección popular.

La representación de las organizaciones provinciales de Unión Patriótica era ejercida por sus presidentes provinciales, la mayoría de ellos antiguos políticos de los partidos turnistas que "corrieron a alistarse en las huestes del vencedor, porque lo único que les interesaba era estar siempre en auge" (Aunós, 1942, p. 302). Aunque el propio Primo de Rivera recomendó una selección previa de los afiliados para evitar que Unión Patriótica se convirtiera en una "agencia de ventajas y colocaciones", no pudo evitar que la red caciquil de la Restauración se infiltrara en la organización (González Calleja, 2005, p. 189-190).

La representación municipal se dilucidaba en unas elecciones de dos grados. En el primero, los alcaldes y concejales de la provincia designaban entre ellos a unos compromisarios que, en segundo grado, elegían al correspondiente asambleísta. Los representantes provinciales eran elegidos entre los miembros de la diputación respectiva (art. 17). Estos procesos electorales distaban de celebrarse con transparencia. Primero, porque los concejales y diputados provinciales eran nombrados indirectamente por el gobierno, a través de los gobernadores civiles y delegados gubernativos — dichos nombramientos se basaban en la previa condición 
de figurar en las listas de adheridos a Unión Patriótica. El partido único pudo, gracias a los "buenos servicios" de los gobernadores civiles, apoderase de la administración municipal y provincial. Como concluye Ben-Ami (1984, p. 151), la mayoría, sino la totalidad, de los asambleístas representantes de las provincias eran upetistas. Por otro lado, el general Martínez Anido, ministro de la Gobernación, no dudó en emplear los viejos métodos de la época de la Restauración para impedir que se introdujeran elementos políticos hostiles. En este sentido, la vieja tesis de Linz (1972, p. 380), quien habla de la "gigantesca discontinuidad" de la clase política de la dictadura respecto al régimen precedente, ha de ser matizada a la luz de los trabajos de Tusell (1977) y, sobre todo, de Gómez Navarro, González Calbet y Portuondo (1980, p. 169), quienes apuntan cómo el caciquismo persistió a todos los niveles y el proclamado regeneracionismo de la dictadura quedó reducido en este aspecto a la nada.

La representación del Estado correspondía "a los directores generales y representantes de Consejos, Patronatos u otros organismos que tengan categoría similar y el Gobierno designe". Los titulares de estos cargos no podían renunciar al escaño; solo perdían la condición de asambleístas cuando cesaban en la administración. Los ministros no podían formar parte de la asamblea, pero sí "intervenir en la labor de ella", razón por la cual tenían un puesto especial y exclusivo en los salones de reuniones (art. 18). Los asambleístas "por derecho propio" se diferenciaban de los representantes del Estado por el hecho de ostentar una serie de cargos que otorgaban de forma automática la categoría de parlamentario, sin mediar el nombramiento intermedio del Gobierno (art. 19): eran los capitanes generales del Ejército y la Armada y el almirante jefe del Estado Mayor de la Armada; los presidentes del Consejo de Estado y de los Tribunales Supremos de Justicia, de Guerra y Marina y de Hacienda Pública; el presidente de la Diputación de la Grandeza; los arzobispos; los fiscales del Tribunal Supremo y de la Rota; los gobernadores del Banco de España e Hipotecario y del Banco de Crédito Local; los presidentes de los Consejos de Trabajo, Instrucción Pública, Superior de Fomento y Superior Bancario y Ferroviario; los que en Madrid y Barcelona ocupaban el cargo de capitán general, gobernador civil, obispo, presidente de la Diputación, alcalde, presidente de la Comisión organizadora de Somatenes y rector de la Universidad; el presidente y secretario general del Comité Nacional de la Unión Patriótica; y también los presidentes y vocales de la Comisión de Codificación y los consejeros permanentes de Estado. Todos ellos hombres de perfil netamente estatal y gubernamental, pues, a excepción de los jerarcas eclesiásticos, eran nombrados directa 0 indirectamente por el gobierno. De hecho, como calculara Linz (1987, p. 571), el 40\% de los asambleístas representantes del Estado y ex officio eran oficiales de alta graduación, dato significativo en un régimen impuesto por un golpe militar. 
La representación de "actividades de la vida nacional" era la que dotaba de mayor perfil corporativo a la asamblea, al integrar a personas designadas libremente por el gobierno, pero con "ponderada representación" de las Reales Academias Española, de la Historia, de Bellas Artes, de Ciencias Exactas, Físicas y Naturales, de Ciencias Morales y Políticas, de Medicina y Jurisprudencia; la enseñanza en sus distintos grados; la agricultura, la industria y el comercio, en su triple matiz patronal, técnico y obrero; la prensa y, en general, "todo cuanto pueda representar manifestación o pugna de intereses ciudadanos" (art. 20). En la práctica, más que la "vida nacional" en su conjunto, este grupo representaba a las clases dominantes y sus intereses, es decir, se trataba de hombres de negocios, banqueros, industriales, comerciantes y terratenientes (González Calbet, 1976, p. 64-68; Gómez Navarro, González Calbet y Portuondo, 1979). El mundo del trabajo quedó infrarrepresentado, aunque la dictadura nombró a siete socialistas que finalmente declinaron la invitación por orden expresa de la Unión General de Trabajadores (Juliá, 1997, p. 125-158; Andrés-Gallego, 1977, p. 155-177). Solo los representantes de los sindicatos católicos y libres acudieron a la llamada del dictador (Winston, 1985, p. 226-292).

Con la intención de paliar el carácter netamente gubernamental de esta última representación, Primo de Rivera impulsó la aprobación de un Decreto-Ley (Gaceta de Madrid, 30-VII-1929, p. 739) que preveía "el ensanchamiento del concepto de corporación" a fin de otorgar asientos específicos en la asamblea a entidades en principio excluidas. De esta manera, se reservaron seis escaños a los Colegios de Abogados y dos a los de Doctores de Madrid y Barcelona; tres para la Real Academia de Jurisprudencia y Legislación; tres para la Real Academia de Ciencias Morales y Políticas; uno para cada una de las Reales Academias Española, de la Historia, de Bellas Artes, de Ciencias y de Medicina, respectivamente; once para las universidades del país; cinco para la Unión General de Trabajadores; dos para la Confederación de Sindicatos Obreros Libres; dos para la Confederación de Sindicatos Obreros Católicos; uno para la Asociación pro-Sociedad de Naciones y otro para la Asociación de Derecho Internacional.

Esta apertura de las bases representativas del régimen con la intención de atraerse a la intelligentsia resultó, sin embargo, un completo fracaso, pues — con las señaladas excepciones de Eugenio D'Ors y Ramiro de Maeztu - los intelectuales rechazaron el régimen de Primo de Rivera (García Queipo de Llano, 1987, p. 476-483). Así, tanto la Unión General de Trabajadores como la Real Academia de Jurisprudencia y Legislación — presidida por el ex ministro Ángel Ossorio — renunciaron a los puestos que se les habían asignado; el Colegio de Abogados de Madrid eligió a José Sánchez Guerra, Santiago Alba y Eduardo Ortega y Gasset, 
abiertos enemigos de la dictadura; la Universidad de Valladolid vio retirado su escaño cuando el claustro eligió por unanimidad a Miguel de Unamuno; y en la Universidad de Oviedo triunfó Melquíades Álvarez frente al candidato oficial.

La asamblea primorriverista se rigió por dos reglamentos: el primero, provisional, de 20 de septiembre de 1927 (Gaceta de Madrid, 21-IX-1927, p. 1.622-1.626); el segundo, definitivo, de 5 de diciembre de 1928 (Gaceta de Madrid, 8-XII-1928, p. 1.557-1.563). Ambos eran heterónomos, es decir, elaborados por el gobierno, lo que revela la falta de autonomía que sufrió la Cámara para establecer su propia regulación interna. El propio Decreto-Ley de creación de la asamblea negaba cualquier autonomía reglamentaria, al preceptuar en su art. 1 que la actividad de aquélla había de quedar "encauzada y dirigida por el Gobierno". De hecho, como señala Fernández Sarasola (2012, p. 75-76), muchos aspectos aparecían tan detalladamente en el Decreto-Ley que los reglamentos se limitaban a regularlos de forma muy exigua, cuando no a reproducir lo contemplado en aquel texto.

Desde el punto de vista organizativo, tanto el presidente de la asamblea como dos de los vicepresidentes y de los secretarios de la mesa eran elegidos por el gobierno (art. 11 del Decreto-Ley), en clara ruptura con el modelo representativo liberal, que garantizaba la autonomía parlamentaria en la designación de sus órganos directivos. El Ejecutivo invadía también las competencias de la Cámara al decidir, de acuerdo con el presidente de ésta, el orden del día de las sesiones plenarias. El presidente de la asamblea gozaba, por lo demás, de amplias competencias: interpretar el reglamento, dirigir las discusiones, aplicar las sanciones disciplinarias, distribuir los trabajos de las secciones, designar a los miembros de estas e incluso presidirlas (art. 12 del Decreto-Ley, arts. 9-18 del Reglamento provisional, y arts. 17-27 del reglamento definitivo). Se comprende cómo, con este perfil, la presidencia se convirtió un mero órgano de control del Ejecutivo sobre los asambleístas (Torres Muro, 1987, p. 163).

Para su trabajo cotidiano, la asamblea fue dividida en dieciocho secciones que, a diferencia de las vigentes en las Cortes del siglo XIX y hasta el reglamento del Congreso de 1918, tenían atribuciones exclusivas para conocer de ciertos asuntos y su composición no dependía del azar. Se trataba, por lo tanto, de un sistema que, a través de una terminología impropia, venía a establecer un modelo de comisiones permanentes (Fraile Clivillés, 1975, p. 327). En efecto, los miembros de las secciones no eran elegidos por los asambleístas, sino nombrados discrecionalmente por el presidente de la Cámara (art. 18 del Decreto-Ley, arts. 37-48 del reglamento provisional, y arts. 44-64 del reglamento definitivo). Junto a las secciones existía una comisión de corrección de estilo y otra de gobierno interior, así como cuantas el presidente de la asamblea considerara necesario crear, a propuesta del gobierno, para realizar investiga- 
ciones (art. 5 del Decreto-Ley, arts. 49-50 y 90-96 del reglamento provisional, y arts. 105-113 del reglamento definitivo).

En torno al método de funcionamiento de la Cámara, el Decreto-Ley imponía restricciones al desarrollo de las sesiones: solo podía haber cuatro plenos al mes, de seis horas de duración cada uno, prorrogables a siete si así lo decidía el presidente de la asamblea (art. 10). Se contemplaba un único período de sesiones, que comprendía desde octubre hasta julio del año siguiente, respetándose las fiestas nacionales y religiosas, así como las vacaciones de Navidad y Semana Santa (art. 6). Las sesiones podían celebrarse a puerta cerrada por decisión del presidente de la Cámara o del gobierno, y los periodistas parlamentarios habían de remitir las galeradas antes de su publicación a una oficina de censura establecida en el mismo palacio de la Carrera de San Jerónimo.

En cuanto a sus facultades, la Asamblea Nacional Consultiva aparecía como un "pseudoparlamento" muy alejado de las Cortes del período precedente (Tamames, 2008, p. 210). Ya el preámbulo del Decreto-Ley aclaraba que "no legislará, no compartirá soberanías; pero, por encargo del Gobierno y aun por iniciativas propias, colaborará en su obra con carácter e independencia garantizadas por su origen, por su composición y por sus fueros". El art. 1 del mencionado texto concretaba que la función de la asamblea era "preparar y presentar escalonadamente al Gobierno, en un plazo de tres años, y con carácter de anteproyectos, una legislación general y completa, que a su hora ha de someterse a un sincero contraste de opinión pública y, en la parte que proceda, a la Real Sanción".

En los preceptos subsiguientes (arts. 2-5) se concretaban otras funciones complementarias de la institución: el enjuiciamiento de la política general "desde el $1^{\circ}$ de julio de 1909", la fiscalización de la acción del gobierno mediante la presentación de interpelaciones dirigidas a sus ministros — quienes podían aceptarlas o rechazarlas en el plazo de ocho días-, la proposición de medidas en el orden económico y la inspección a instancias del gobierno de determinados servicios y organismos del Estado.

El art. 9 del Decreto-Ley establecía el iter que los citados anteproyectos habían de seguir para su aprobación. El presidente de la Cámara, de acuerdo con el gobierno, encargaba a las secciones el estudio o dictamen de los asuntos de su especialidad, aunque éstas también podían tener iniciativas propias. Una vez aprobado por la mayoría de la sección un estudio 0 dictamen, se elevaba al presidente de la asamblea, "quien lo pasará al Gobierno, quien resolverá sobre la toma en consideración y su pase al Pleno". Suponiendo que un dictamen hubiera sido del agrado del gabinete y pasara a discusión del pleno de la Cámara, una vez reunida ésta, "la Presidencia, de acuerdo con el Gobierno, resolverá si ha de recaer votación y, en caso afirmativo, por qué procedimiento". En fin, se trataba de un procedimiento que reforzaba el 
férreo control del Ejecutivo y "parecía pensado para una Asamblea formada por los más decididos opositores de la dictadura" (Gómez Navarro, 1991, p. 270).

Las limitaciones impuestas determinaron que los asuntos tratados por la asamblea carecieran, por lo general, de interés para la vida del país y no influyeran decisivamente en la política desplegada por Primo de Rivera. Las cuestiones estrictamente políticas apenas se trataron, salvo alguna intervención aislada del tradicionalista Víctor Pradera en defensa de un regionalismo foral enfrentado a la política centralista del Gobierno (DSAN, 16-I-1928, p. 243-260). En cuanto a los debates sobre educación, los más importantes estuvieron dedicados al nuevo plan de estudios de bachillerato, a propuesta de Pedro Sainz Rodríguez (DSAN, 29-X-1927, p. 16-26), y a la reforma universitaria impulsada por el ministro Eduardo Callejo tras una enmienda firmada, entre otros, por el conde de los Andes, Esteban Bilbao y Enrique Herreros de Tejada, quienes pedían la adecuación de la educación superior estatal a los planes de las universidades privadas jesuitas y agustinas (DSAN, 15-II-1928, ap. $1^{\circ}$ ).

Se produjo en la Cámara un desplazamiento de las discusiones hacia temas de carácter económico, social y técnico-jurídico. Dos ejemplos de ello lo constituyen los debates en torno a los presupuestos de 1929 y el llamado "problema económico de España", que dio lugar a diversas intervenciones sobre el proteccionismo y el intervencionismo del Estado (DSAN, 16, 17, 18, 19 y 20-I-1928, p. 260-277, 304-320, 347-362, 381-404 y 406-452). Estos debates muestran claramente la inoperancia de la Cámara, marcada por su propia naturaleza corporativa: los representantes actuaban en función de unos intereses muy determinados, a los que se debían y que intentaban defender, mostrando la dificultad de que se produjera una confluencia de todas las sensibilidades. En este ambiente, en que prácticamente todas las intervenciones eran una defensa de los más estrictos intereses de grupo, las palabras de los ministros, de algunos asambleístas — como Vicente Gay o Antonio Flores de Lemus, economistas que hablaban con independencia de intereses - e incluso del propio Primo de Rivera, resultaban aisladas y fracasaron a la hora de centrar las discusiones para convertirlas en algo útil. Con razón pudo decir Velarde Fuertes (1968, p. 92) que "la exteriorización de opiniones archiconocidas fue el único resultado del acceso corporativo a la Asamblea".

Otro de los aspectos negativos de la metodología de trabajo de la asamblea era la falta de un plan de conjunto mínimamente organizado que evitara duplicaciones. Así, a veces la Cámara ocupaba su tiempo en debatir cuestiones que paralelamente estaban estudiando otros organismos del Estado — por ejemplo, mientras la Comisión General de Codificación recababa datos para una modificación del Código Penal, la Cámara dedicó varias sesiones en el mismo sentido (DSAN, 20-I-1928, p. 405). En otras ocasiones, la asamblea actuaba al dictado de impulsos arbitrarios o frívolos del dictador (Maura, 1930, v. Il: 77), consumiendo su tiempo 
en "problemas" que no preocupaban a la opinión pública, como la restauración del palacio de Sada, en Sos (Zaragoza), lugar de nacimiento de Fernando el Católico (DSAN, 31-X-1928, p. 84-92), o el límite adecuado para la sucesión ab intestato (DSAN, 24, 25 y 26-XI-1927, p. 84-105, 128-147 y 172-190).

Habida cuenta de esta inoperancia se explica por qué los contemporáneos de la asamblea no prestaron demasiada atención a sus debates por qué, cuando lo hicieron, no tomaran a sus protagonistas en serio, provocando sátiras clandestinas como la recogida por Sainz Rodríguez (1978, p. 85), atribuida a Luis de Tapia: "Y de cabrones, ¿qué?/ ¡Pues a montones/ han ido a la Asamblea/ los cabrones!". Era lógico, pues todos sabían que el gobierno controlaba tanto la composición como el funcionamiento interno y que la Cámara solo era representativa de un sector del país: el de los políticos que colaboraban con la dictadura y el de los intereses dominantes en la sociedad. La asamblea, en consecuencia, no cumplió con la primera de las funciones que le habían sido asignadas: la de "intervenir en la actualidad". Nunca inspeccionó actuaciones ni enjuició gestiones de la administración. Los escasos intentos de crítica a la política gubernamental, realizados principalmente por Sainz Rodríguez y Pradera, fueron sofocados por el gobierno, teniendo incluso que intervenir el propio dictador, dada la falta de autoridad de los ministros y directores generales para contestar.

El valor de la asamblea de Primo de Rivera reside, por lo tanto, no en sus potestades efectivas, sino en el hecho de haberse erigido en foro en el que encontraron asiento antiguas figuras del conservadurismo dinástico que la dictadura supo reciclar en su provecho: el conde de Bugallal, Juan de la Cierva, Antonio Goicoechea, César Silió y tantas otras personalidades que encarnaban no solo el poder político caciquil sino también el poder económico a través de su presencia en numerosos consejos de administración (Tuñón de Lara, 1967, p. 120). El objetivo era que la asamblea se convirtiera en un futuro en la base para la creación de un sistema autoritario corporativo, evitando que el rey quedara desprovisto de un órgano deliberante en el que estuvieran las "figuras prominentes" en caso de que el gobierno cayese (Ben-Ami, 1980, p. 121). Los acontecimientos impidieron que pudiera cumplir este cometido, si bien la combinación de corporativismo y democracia controlada que significó sirvió de inspiración técnica y operativa a las cortes estatuidas por el franquismo en 1942 (Giménez Martínez, 2012, p. 73-81).

\section{LAS CORTES DEL ANTEPROYECTO CONSTITUCIONAL DE 1929}

\footnotetext{
L a asamblea no se concibió solo como órgano representativo, sino como instancia endictadura, dada la inconveniencia de restaurar una Constitución, la de 1876, que el propio
} 
rey había violado al aceptar el golpe de Primo de Rivera y que en todo caso encarnaba un sistema político caduco, propio de una sociedad agraria y caciquil en trance de desaparecer (Cambó, 1927, p. 192). La tarea corrió a cargo de la Sección Primera de la Asamblea, integrada por quince hombres procedentes en su mayoría del tradicionalismo, el maurismo y el catolicismo social, si bien los más influentes fueron Gabriel Maura y Antonio Goicoechea, con algunas concesiones finales a Juan de la Cierva (García Canales, 1980, p. 41). La sección primera aprobó un anteproyecto de Constitución en junio de 1928 y un año después, en mayo de 1929, ultimó una serie de leyes orgánicas complementarias. El conjunto resultante fue un amplísimo código de medio millar de artículos que se proponía levantar un nuevo Estado de carácter conservador, corporativo, intervencionista y antidemocrático (Gómez Navarro, 1991, p. 294-295).

Así, el anteproyecto de Constitución declaraba a la Monarquía "sagrada e inviolable" (art. 43), declaraba la religión católica como oficial del Estado, prohibiendo las manifestaciones públicas de otros cultos (art. 11), y proclamaba un centralismo radical (arts. 1, 2, 8, 9, 87, 88 y 89). En el área económica, defendía un papel activo de la administración en la organización del sistema productivo (arts. 79 y 80) e incluso preveía el reconocimiento de algunos derechos sociales, como la protección de la infancia y su educación (art. 24) o el seguro de salud, vejez, enfermedad y accidentes (art. 28), que estaban en línea con lo dispuesto por el Código del Trabajo de 1926, influido por el corporativismo fascista y la doctrina social de la Iglesia (Varela Suanzes-Carpegna, 2012, p. 102). Los derechos ciudadanos eran enunciados de forma genérica y podían ser suspendidos por el gobierno en caso de "evidente riesgo exterior para la seguridad del Estado o de grave perturbación interior que amenace o comprometa la paz general" (art. 72), hecho que llevó a decir a Zancada (1930, p. 106) que el Ejecutivo "por su propia voluntad queda convertido en dictador, pudiendo hacer durar este estado excepcional cuanto tiempo quiera". Desaparecían los conceptos liberales de soberanía nacional y separación de poderes. La soberanía pasaba a tener un origen indefinido y solo se reconocía al titular de la misma: el Estado, como "órgano representativo permanente de la nación" (art. 4).

En cuanto a la organización de los poderes, el art. 6 del anteproyecto aludía al "doble principio de diferenciación y coordinación", fórmula vacía de contenido en tanto el poder del rey sobresalía sobre el resto de instituciones —al monarca correspondía iniciar cualquier reforma constitucional (art. 102), era jefe del Ejecutivo, tenía libertad para nombrar y cesar a sus ministros (arts. 69-70) y hasta de interferir en el poder judicial, al deber cuidar de que "en su nombre se administre justicia pronta y cumplida" (art. 43).

La visión de la sociedad del anteproyecto era la de una trama con escalones sucesivos en su organización: familia, municipio —entendido en el art. 87 como "asociación natural 
de personas y bienes" - , provincia y Estado, pero sin figurar dentro de él ningún esquema de sindicatos, aportación que se hará ya en los años 1930. Esta visión general corporativa se concretará en la existencia de unas cortes unicamerales y semiorgánicas, con un mandato de cinco años de duración (art. 54), cuyos diputados serían elegidos por los españoles de ambos sexos mayores de 25 años (art. 55). El número máximo de diputados sería de 412, repartidos en tres grupos (art. 56), con 206 elegidos por sufragio universal directo, a razón de uno por cada 100 mil habitantes; 30 vitalicios designados por el rey; y 176 elegidos en colegios especiales de profesiones o clases atendiendo a la siguiente distribución: 50 diputados elegidos por las diputaciones provinciales y compromisarios de los ayuntamientos; 18 por las cámaras agropecuarias; 18 por las cámaras de comercio y navegación; 18 por las cámaras de industria; 18 por las cámaras de propiedad; 18 por los colegios de abogados, procuradores de los tribunales, médicos, farmacéuticos, ingenieros, doctores y otros para cuyo ejercicio se requiriese título universitario; 18 por las "asociaciones profesionales obreras"; y 18 por los claustros universitarios, reales academias y otros organismos de índole científica o artística.

Con ello, la Cámara adquiría tintes corporativos indudables, lo que hizo sacar la conclusión al periódico El Debate —órgano de expresión de la Asociación Católica Nacional de Propagandistas - de que la aristocracia histórica sería sustituida por una "aristocracia cultural y económica" (Ben-Ami, 1984, p. 159).

El art. 59 del anteproyecto, al disponer que "las Cortes se reunirán anualmente durante un período que, en cada año natural, no será menor de cuatro meses", otorgaba cierta autonomía funcional al Legislativo. Correspondía al rey, sin embargo, convocar, disolver, suspender y cerrar las sesiones. Además, a diferencia de lo que se había previsto para la asamblea consultiva, el art. 61 reconocía expresamente la facultad de la cámara de elaborar su propio reglamento y elegir tanto a su presidente como al resto de sus órganos de dirección. Este mismo precepto hacía referencia a la capacidad de las cortes para examinar la validez de las actas, la publicidad de las sesiones como norma y la necesidad de un quórum de la mitad más uno de los diputados para adoptar resoluciones.

En el aspecto funcional, las cortes del anteproyecto tenían conferida la facultad legislativa, pero carecían de iniciativa en política exterior, defensa nacional, rebaja de contribuciones 0 aumento de gastos presupuestarios (art. 62). No obstante, tenían reservadas atribuciones en una veintena de materias enumeradas en el art. 63, entre las que destacan el examen de los presupuestos y cuentas públicas, la inspección de las operaciones económicas, la fijación bienal de las fuerzas militares, la determinación del régimen al que habían de someterse los procesos electorales, la delimitación de las condiciones para el ejercicio de los derechos, el 
establecimiento de las bases para la organización de los distintos poderes del Estado y la concesión de amnistías. Así pues, las facultades legislativas de la Cámara, aunque eran superiores a las de la asamblea, no podían comparase con las de cualquier Parlamento liberal.

El anteproyecto no preveía que las cortes tuvieran autoridad para vigilar la actividad del Ejecutivo ni que el gobierno tuviera que rendir cuentas ante ellas. Y ello porque, como recuerda Tomás Villarroya (1981, p. 134), el art. 66 del anteproyecto procuraba establecer cierta separación entre el gobierno y las cortes que favoreciese la estabilidad del primero: de una parte, declaraba la incompatibilidad entre el cargo de ministro y la condición de diputado; de otra, prescribía que las cortes no podrían adoptar acuerdos que significasen confianza o censura respecto del gobierno. En todo caso, el rey (art. 52 in fine) o el Consejo del Reino —órgano consultivo integrado por altos cargos del Ejército, la administración y la nobleza diseñado para asesorar al monarca (arts. 44-53) - podían vetar cualquiera de sus iniciativas.

En principio se pensó en promulgar el anteproyecto de Constitución con la simple rúbrica del rey. Sin embargo, el peligro de que este método convirtiera al texto en una simple carta otorgada llevó a Primo de Rivera a optar por otro procedimiento: se requeriría a los ex presidentes del consejo de ministros, a quienes hubieran presidido cualquiera de las dos Cámaras constitucionales, y también a los que hubieran ostentado la presidencia del Consejo de Estado, que aceptasen el cargo de asambleístas, de modo que la Constitución fuera sancionada por una asamblea así reforzada.

Sin embargo, después de muchas dudas, todos ellos rechazaron el ofrecimiento: el conde de Romanones, tal vez el más significado de los "viejos políticos" de la Restauración, era consciente de que el régimen de Primo de Rivera no sobreviviría mucho tiempo y decidió centrarse en apoyar al rey para desvincularlo del fracaso en ciernes de la dictadura. En ese trace, durante el verano de 1929, el dictador ordenó que el anteproyecto constitucional y las leyes anejas se publicasen, levantándose excepcionalmente la censura de prensa para favorecer la toma de posición de las diferentes sensibilidades políticas respecto a su contenido. Fue en ese momento cuando todos los sectores más o menos liberales, desde la derecha conservadora a la izquierda más democrática y republicana, también la socialista, mostraron su común oposición a los propósitos constituyentes de la dictadura (Álvarez Chillida, 1996).

En realidad, el anteproyecto no satisfacía a nadie, ni al propio Primo de Rivera, molesto con los amplios poderes que se le concedían al rey en detrimento del gobierno y su presidente. Todavía en el consejo de ministros celebrado el último día de 1929, el dictador planteó al rey una salida alternativa: formar un gobierno presidido por un civil "de corte derechista" — tanto Ben-Ami (1984, p. 342-343) como González Calleja (2005, p. 374) apuntan al conde de Gua- 
dalhorce - y reunir una nueva asamblea de 500 miembros, mitad con carácter de senadores y mitad de diputados, que preparara una nueva Constitución. Pero fue un esfuerzo inútil, así que Alfonso XIII ya se planteaba decididamente la conveniencia de desembarazarse de Primo de Rivera, habida cuenta de la acumulación y agravamiento de problemas en el país (García Queipo de Llano, 1997, p. 116). Abandonado por su principal valedor, Primo de Rivera dimitió el 28 de enero de 1930 y fue sustituido por el general Dámaso Berenguer, jefe de la casa militar del rey.

A Berenguer se le encargó la tarea de arbitrar un retorno controlado a la Constitución de 1876, previa celebración de elecciones libres. Con ese objetivo, el 16 de febrero de 1930 disolvió la Asamblea Consultiva, anunciando la celebración de comicios para el restablecimiento de las cortes conforme a lo preceptuado por el texto constitucional canovista. Pero para entonces el apoyo a Alfonso XIII y a la Monarquía tout court como forma de Estado y de gobierno había menguado de forma muy considerable. El desprestigio del régimen era completo y resultaba irreversible el daño que el propio rey le había ocasionado al auspiciar y arropar a la dictadura. Los meses siguientes fueron, así pues, "un plano inclinado hacia la República" (Seco Serrano, 1969, p. 173) en el que cristalizó el Pacto de San Sebastián suscrito por fuerzas republicanas, socialistas y regionalistas para la creación de un comité revolucionario que coordinara esfuerzos en pro del derribo de la Monarquía.

Berenguer dimitió el 14 de febrero de 1931. Tras el intento fallido de entregar el gobierno a José Sánchez Guerra y Melquíades Álvarez, el rey nombró presidente al almirante Juan Bautista Aznar, que se apresuró a convocar elecciones municipales para el 12 de abril con la idea de transmitir una imagen de normalidad constitucional. El Ejecutivo trató de conceder a los comicios una dimensión estrictamente administrativa, pero los republicanos los convirtieron en un juicio contra el régimen. Un hecho que adquiere sentido si se tiene en cuenta que solo sistemas políticos tambaleantes y previamente deslegitimados se someten a estos plebiscitos encubiertos, sintiéndose afectados por unas votaciones que saben les son particularmente dirigidas. Los resultados, globalmente considerados, dieron el triunfo a los concejales monárquicos, pero de su análisis cualitativo se desprende el éxito innegable de los candidatos antimonárquicos: 41 de las 50 capitales de provincia, en donde la acción del caciquismo apenas tenía peso, tuvieron una mayoría de concejales republicanos y socialistas. En Madrid, los concejales republicanos doblaban a los monárquicos y, en Barcelona, los triplicaban (Martínez Cuadrado, 1969, v. II, p. $851-857$ y 998-999; Tusell, 1969, p. 182 y ss.). Las calles se llenaron entonces de jubilosos manifestantes que pedían la inmediata proclamación de la República. Dos días después, Aznar anunció la dimisión en bloque de su gobierno y Alfonso XIII huyó del país. 


\section{REFERENCIA BIBLIOGRÁFICA}

AGESTA, Luís Sánchez. Historia del constitucionalismo español. 3 ed. Madrid: Instituto de Estudios Políticos, 1974.

ANDRÉS-GALLEGO, José. El socialismo durante la dictadura (1923-1930). Madrid: Tebas, 1977.

AUNÓS, Eduardo. España en crisis (1874-1936). Buenos Aires: Librería del Colegio, 1942.

BEN-AMI, Shlomo. Hacia una comprensión de la dictadura de Primo de Rivera. Revista de Derecho Político de la Uned, n. 6, p. 107-132,1980.

BOFARULL, Manuel de. Las antiguas Cortes. El moderno Parlamento. El régimen representativo orgánico. Revista de Archivos, Bibliotecas y Museos, Madrid, 1912.

CALBET, María Teresa. Aproximación al estudio de la Asamblea Nacional Consultiva de Primo de Rivera, 1927-1930. Madrid: Universidad Autónoma de Madrid, 1976.

CALLEJA, Eduardo González. La España de Primo de Rivera. La modernización autoritaria: 1923-1930. Madrid: Alianza, 2005.

CANALES, Mariano García. El problema constitucional en la dictadura de Primo de Rivera. Madrid: Centro de Estudios Constitucionales, 1980.

. La teoría de la representación política en la España del siglo XX. Murcia: Universidad de Murcia, 1977. Los intelectuales y la dictadura de Primo de Rivera. Madrid: Alianza, 1987.

CAMBÓ, Francisco. Por la concordia. Madrid: Compañía Iberoamericana de Publicaciones, 1927.

CHILLIDA, Gonzalo Álvarez. El fracaso de un proyecto autoritario: el debate constitucional en la Asamblea Nacional de Primo de Rivera. Revista de Estudios Políticos, n. 93, p. 359-3751, 1996.

CLIVILLÉS, Manuel Fraile. Introducción al derecho constitucional español. Madrid: Rivadeneyra, 1975.

CUADRADO, Miguel M. Elecciones y partidos políticos en España, 1868-1931. Madrid: Taurus, 1969. La dictadura de Primo de Rivera, 1923-1930. Barcelona: Planeta, 1984.

CUEVAS, Pedro Carlos González. El pensamiento político de la derecha española del siglo XX. Madrid: Tecnos, 2005.

DÍAZ-PLAJA, Fernando. La historia de España en sus documentos: el siglo XX. Dictadura y República, 19231936. Madrid: Instituto de Estudios Políticos, 1965.

FERNÁNDEZ, Paloma Díaz. La dictadura de Primo de Rivera: una oportunidad para la mujer. Espacio, Tiempo y Forma. Serie V, Historia Contemporánea, n. 17, p. 175-190, 2005.

FUERTES, Juan Velarde. Política económica de la dictadura. Madrid: Guadiana, 1968.

GARCÍA-NIETO, María Carmen; DONÉZAR, Javier; PUERTA, Luís Lópes. La dictadura, 1923-1930. Bases documentales de la España contemporánea. Madrid: Guadiana, 1973.

GOICOECHEA, Antonio. La crisis del constitucionalismo moderno. Madrid: Voluntad, 1925.

HERR, Richard. Ensayo histórico de la España contemporánea. Madrid: Pegaso, 1977. 
JULIÁ, Santos. Los socialistas en la política española (1879-1982). Madrid: Taurus, 1997.

LARA, Manuel Tuñón de. Historia y realidad del poder: el poder y las élites en el primer tercio de la España del siglo XX. Madrid: Edicusa, 1967. . La España del siglo XX. París: Librería Española, 1966.

LLANO, Genoveva Queipo de. El reinado de Alfonso XIII: la modernización fallida. Madrid: Historia 16, 1997.

LINZ, Juan J. Continuidad y discontinuidad en la élite política española: de la Restauración al régimen actual. In: DÍAZ, E.; MORODO, R. (Eds.). Estudios de ciencia política y sociología: homenaje al profesor Carlos Ollero. Madrid: Gráficas Carlavilla, 1972, p. 361-423.

MARTíNEZ, Miguel Ángel. Historia del parlamentarismo español. Madrid: Centro de Estudios Políticos y Constitucionales, 2017. . Las cortes españolas en el régimen de Franco. Madrid: Congreso de los Diputados, 2012.

MAURA, Gabriel. Bosquejo histórico de la dictadura. Madrid: Tipografía de Archivos, 1930.

MELLA, Juan Vázquez de. Una antología política. Ed. y estudio preliminar de ARÓSTEGUI, Julio. Oviedo: Principado de Asturias, 1999.

MIRKINE-GUETZÉVITCH, Boris. La nouvelle Constitution espagnole. L'Europe Nouvelle, n. 539, p. 796-798,1928.

MORODO, Raúl. Acción española: orígenes ideológicos del franquismo. Madrid: Túcar, 1980.

MURO, Ignacio Torres. Los órganos de gobierno de las Cámaras. Madrid: Congreso de los Diputados, 1987.

NAVARRO, José Luís Gómez. El régimen de Primo de Rivera: reyes, dictaduras y dictadores. Madrid: Cátedra, 1991.

. La Unión Patriótica: análisis de un partido del poder. Estudios de Historia Social, n. 32-33, 1985, p. $93-161$.

; CALBET, María Teresa González; PORTUONDO, Ernesto. Aproximación al estudio de las élites políticas en la dictadura de Primo de Rivera. Cuadernos Económicos de Información Comercial Española, n. 10, 1979, p. 183-208.

- La Asamblea Nacional Consultiva: poder económico y poder político en la dictadura de Primo de Rivera. Estudios de Historia Social, n. 14, p. 157-188, 1980.

. La Asamblea Nacional de Primo de Rivera. In: Política y sociedad: estudios en homenaje a Francisco Murillo Ferrol. Madrid: Centro de Investigaciones Sociológicas/Centro de Estudios Constitucionales, v. II, 1987, p. 559-582.

PELOILLE, Manuelle. Fascismo en ciernes. España, 1922-1930. Textos recuperados. Toulouse: Presses Universitaires du Mirail, 2005.

PEMÁN, José María (Ed.). El pensamiento de Primo de Rivera: sus notas, artículos y discursos. Madrid: Sáez Hermanos, 1929.

PRADERA, Victor. El Estado Nuevo. Madrid: Cultura Española, 1941.

RODRÍGUEZ, Pedro Sainz. Testimonios y recuerdos. Barcelona: Planeta, 1978. 
SARASOLA, Ignacio Fernández. Parlamentarismo. In: SEBASTIÁN, Javier Fernández; FUENTES, Juan Francisco. Diccionario político y social del siglo XX español. Madrid: Alianza, 2008, p. 900-906.

Reglamentos parlamentarios (1810-1977). Madrid: lustel, 2012.

SCHMITT, Carl. La dictadura. Madrid: Revista de Occidente, 1968.

SEGARRA, Rosa Martínez. La Unión Patriótica. Cuadernos de la Cátedra Fadrique Furió Ceriol, n. 1, 1992, p. 67-75.

La proyección constitucional de la dictadura. La Asamblea Nacional Consultiva (I). Boletín Informativo de Ciencia Política, n. 13-14, 1973, p. 83-89.

SERRANO, Carlos Seco. Alfonso XIII y la crisis de la Restauración. Barcelona: Ariel, 1969.

SUANZES-CARPEGNA, Joaquín Varela. Constituciones y leyes fundamentales. Madrid: lustel, 2012.

SUEIRO, Susana. Las relaciones diplomáticas hispano-italianas durante la dictadura de Primo de Rivera (1923-1930). Madrid: Universidad Autónoma de Madrid, 1983.

TAMAMES, Ramón. Ni Mussolini ni Franco: la dictadura de Primo de Rivera y su tiempo. Barcelona: Planeta, 2008.

TUSELL, Javier. La crisis del caciquismo andaluz (1923-1931). Madrid: Cupsa, 1977.

; SAZ, Ismael. Mussolini y Primo de Rivera: las relaciones políticas y diplomáticas de dos dictaduras mediterráneas. Boletín de la Real Academia de la Historia, vol. CLXXIX, n. 3, p. 413-483, 1982.

Sociología electoral de Madrid, 1903-1931. Madrid: Edicusa, 1969.

- Radiografía de un golpe de Estado: el ascenso al poder del general Primo de Rivera. Madrid: Alianza, 1987.

VILLARROYA, Joaquín Tomas. Breve historia del constitucionalismo español. Madrid: Centro de Estudios Constitucionales, 1981.

WINSTON, Colin M. Workers and the Right in Spain, 1900-1936. Princeton: Princeton University Press, 1985. ZANCADA, Práxedes. Los problemas constitucionales de España. Madrid: Compañía Iberoamericana de Publicaciones, 1930. 
